\title{
Genome Resources for Thelonectria rubi, the Causal Agent of Nectria Canker of Caneberry
}

\author{
Demetra N. Skaltsas ${ }^{1,2}$ and Catalina Salgado-Salazar ${ }^{1, \dagger}$ \\ ${ }^{1}$ Mycology and Nematology Genetic Diversity and Biology Laboratory, United States Department of \\ Agriculture-Agriculture Research Service (USDA-ARS), 10300 Baltimore Avenue, Beltsville, MD 20705, \\ U.S.A. \\ ${ }^{2}$ Oak Ridge Institute for Science and Education, ARS Research Participation Program, MC-100-44, P.O. \\ Box 117, Oak Ridge, TN 37831, U.S.A.
}

\begin{abstract}
Thelonectria rubi is the causal agent of Nectria canker of Rubus spp. Here, we report a highquality draft genome sequence for this pathogen, which also represents the first genome sequence for a Thelonectria species. The genome assembly was $44.6 \mathrm{Mb}$ in size, assembled into 669 scaffolds and consisting of 12,973 predicted protein-coding genes. The availability of genome data for $T$. rubi provides a critical additional resource for an important plant pathogen and will be useful for fungal biology, comparative genomic, taxonomic and population studies of this and related species.
\end{abstract}

Thelonectria rubi (Osterw.) C. Salgado \& P. Chaverri is a fungal pathogen in the Nectriaceae family (Salgado-Salazar et al. 2015, 2016) and causal agent of Nectria canker of caneberry. This fungus was first observed in Switzerland causing root cankers of raspberry and was described by A. Osterwalder as Nectria rubi (Osterwalder 1911). Since this first observation, disease outbreaks have been reported in several countries, including Australia, England, Ireland, New Zealand, Scotland, and Venezuela (Farr and Rossman 2019; Martin et al. 2017), on a variety of hosts; namely, Rubus glaucus, R. idaeus, and R. fruticosus (Farr and Rossman 2019). Disease symptoms include dark-brown or purplish vascular lesions located on roots and crowns. These lesions generally produce wilting of lateral shoots, which can lead to cane death or reduction or complete absence of production of primocanes during the growing season (Cedeño et al. 2004; Martin et al. 2017). Clusters of reddish perithecia representing the sexual state of the fungus can be found on the transition region between the roots and canes of dead plants or plants in advanced stages of the disease (Booth 1966; Martin et al. 2017). Management of this pathogen is restricted to cultural practices that protect cane bases and crowns from environmental stresses such as high winds, humidity, and waterlogging (Martin et al. 2017). Because T. rubi has been reported to affect stressed plants, it has been regarded as a secondary or weak pathogen (Martin et al. 2017). The genomic resource generated in this study provides a reference not only for genetic and comparative genome analyses but also for taxonomic studies in the genus Thelonectria and the family Nectriaceae, which harbor a variety of widespread and destructive plant pathogens (Lombard et al. 2015).

Mycelial tissue of $T$. rubi CBS 177.27 (= IMI 113917) isolated from R. idaeus roots in England was grown on potato dextrose agar at $20^{\circ} \mathrm{C}$ for 7 days, after which mycelial tissue along

\footnotetext{
${ }^{\dagger}$ Corresponding author: C. Salgado-Salazar; catalina.salgado@usda.gov

Current address of D. N. Skaltsas: Diné College, School of Science, Technology, Engineering, and Mathematics, 1 Circle Drive, Tsaile, AZ 86556, U.S.A.
}

The author(s) declare no conflict of interest.

Accepted for publication 3 January 2020.

\section{Funding}

This work was supported by funds from USDA-ARS project 8042-22000-298-00$\mathrm{D}$ and by the appointment of D. N. Skaltsas to the ARS Research Participation Program administered by the Oak Ridge Institute for Science and Education (ORISE) through an interagency agreement between the U.S. Department of Energy (DOE) and the USDA. ORISE is managed by Oak Ridge Associated Universities under DOE contract number DE-AC05-06OR23100.

\section{Keywords}

analytical and theoretical plant pathology, Nectriaceae, Nectria canker, Rubus 
Table 1. Summary statistics of the draft genome assembly of Thelonectria rubi

\begin{tabular}{|c|c|}
\hline Isolate & CBS $177.27(=\mathrm{IMI} 113917)$ \\
\hline Total length $(\mathrm{Mb})$ & 44.6 \\
\hline Number of scaffolds & 669 \\
\hline Maximum scaffold length $(\mathrm{kb})^{\mathrm{a}}$ & $1,453.5$ \\
\hline Average scaffold size $(\mathrm{kb})$ & 66.6 \\
\hline Average coverage & $208.6 x$ \\
\hline $\mathrm{N}_{50}(\mathrm{~kb})^{\mathrm{b}}$ & 303.6 \\
\hline GC content $(\%)$ & 50.8 \\
\hline Eukaryote orthologs ${ }^{c}$ & $96.8 \%$ \\
\hline Fungal orthologs ${ }^{d}$ & $99.1 \%$ \\
\hline Predicted gene models & 12,973 \\
\hline Transposable elements ${ }^{\mathrm{e}}$ & $11.396 \%$ \\
\hline
\end{tabular}

a Minimum scaffold length $=500 \mathrm{bp}$.

b Scaffold or contig length at which $50 \%$ of the total assembly length is covered.

c Percentage of complete BUSCOs found, 429 total BUSCO groups searched.

d Percentage of complete BUSCOs found, 1,438 total BUSCO groups searched.

e Percentage of the nuclear genome containing transposable elements.

with media were excised from plates and blended with Difco potato dextrose broth medium at $50 \%$ concentration. Mycelial tissue was then grown with constant shaking $(125 \mathrm{rpm})$ at $20^{\circ} \mathrm{C}$ for 3 days. Genomic DNA was extracted using the OmniPrep DNA kit (G-Biosciences, St. Louis, MO, U.S.A.). Genomic DNA libraries were constructed using the TruSeq DNA Nano kit and sequenced on an Illumina MiSeq as $2 \times 300$ paired-end reads using a MiSeq 600-cycle reagent kit (version 3.0; Illumina, San Diego, CA, U.S.A.). After trimming for quality and adapter removal, 49.2 million reads were obtained. A de novo genome assembly was performed in CLC Genomics Workbench (version 12; CLC Bio, Boston, MA, U.S.A.) using kmer $=50$ and bubble $=36$. A summary of the genome assembly statistics is provided in Table 1. The 44.6-Mb T. rubi genome assembly size is consistent with the known range of genome sizes of species in closely related genera in the Nectriaceae family such as Calonectria (53 to $65 \mathrm{Mb}$ ) (Malapi-Wight et al. 2019), Corinectria (39 Mb) (Salgado-Salazar and Crouch 2019), Dactylonectria (58 Mb) (MalapiWight et al. 2015), and Neonectria (40 to $44 \mathrm{Mb}$ ) (Deng et al. 2015; Salgado-Salazar and Crouch 2019). Gene model predictions using the AUGUSTUS web server (Hoff and Stanke 2013) using Fusarium graminearum gene models identified a total of 12,973 genes for T. rubi. Analysis of putative enzymes associated with the biosynthesis of secondary metabolites using antiSMASH fungal version (https://fungismash.secondarymetabolites.org/) (Medema et al. 2011) identified 27 secondary metabolite clusters, including 8 type I polyketide synthases and 14 nonribosomal peptide synthetase clusters. The presence of the MAT1-1 and MAT1-2 idiomorphs in the genome assembly of $T$. rubi was determined by performing a local BLASTn search against a MAT gene database (Rivera et al. 2018). Only the conserved $\alpha$ domain, indicative of the MAT1-1 mating type, was identified in the contig 28 of this isolate, indicating that $T$. rubi is likely a heterothallic species. Transposable element (TE) analysis using REPET version 2.5 (Flutre et al. 2011), following the protocol detailed by Rivera et al. (2018), indicated that TEs comprised $11.4 \%$ of the $T$. rubi draft genome. Evidence of repeat-induced point (RIP) mutations was detected in 379 dictyostelium repetitive sequences (DIRS) and 16 Helitron TEs.

The Whole Genome Shotgun project described in this work was deposited at DNA Data Bank of Japan/European Nucleotide Archive/GenBank under accession number WMHX00000000 (BioProject ID PRJNA590790). Whole-genome gene predictions and raw sequencing reads are available through the National Agricultural Library AgData Commons. Voucher specimens and the fungal isolate used in this study are available at the Fungal Biodiversity Institute (CBS) in Utrecht, The Netherlands.

\section{Acknowledgments}

Mention of trade names or commercial products in this publication is solely for the purpose of providing specific information and does not imply recommendation or endorsement by the USDA. The USDA is an equal opportunity provider and employer. 


\section{Literature Cited}

Booth, C. 1966. The genus Cylindrocarpon. Mycol. Pap. 104:1-56.

Cedeño, L., Carrero, C., Quintero, K., Pino, H., and Espinoza, W. 2004. Cylindrocarpon destructans var. destructans and Neonectria discophora var. rubi associated with black foot rot on blackberry (Rubus glaucus Benth.) in Merida, Venezuela. Interciencia 29:455-460.

Deng, C. H., Scheper, R. W. A., Thrimawithana, A. H., and Bowen, J. K. 2015. Draft genome sequences of two isolates of the plant-pathogenic fungus Neonectria ditissima that differ in virulence. Genome Announce. 3:e01348-15.

Farr, D. F., and Rossman, A. Y. 2019. Fungal Databases U.S. National Fungus Collections. United States Department of Agriculture-Agriculture Research Service. https://nt.ars-grin.gov/fungaldatabases/

Flutre, T., Duprat, E., Feuillet, C., and Quesneville, H. 2011. Considering transposable element diversification in de novo annotation approaches. PLoS One 6:e16526.

Hoff, K. J., and Stanke, M. 2013. WebAUGUSTUS-A web service for training AUGUSTUS and predicting genes in eukaryotes. Nucleic Acids Res. 41: W123-W128.

Lombard, L., van der Merwe, N. A., Groenewald, J. Z., and Crous, P. W. 2015. Generic concepts in Nectriaceae. Stud. Mycol. 80:189-245.

Malapi-Wight, M., Salgado-Salazar, C., Demers, J., Veltri, D., and Crouch, J. A. 2015. Draft genome sequence of Dactylonectria macrodidyma, a plant-pathogenic fungus in the Nectriaceae. Genome Announce. 3:e00278-15.

Malapi-Wight, M., Veltri, D., Gehesquiere, B., Heungens, K., Rivera, Y., SalgadoSalazar, C., and Crouch, J. A. 2019. Global distribution of mating types shows limited opportunities for mating across populations of fungi causing boxwood blight disease. Fungal Genet. Biol. 131:103246.

Martin, R. R., Ellis, M. A., Williamson, B., and Williams, R. N. 2017. Compendium of Raspberry and Blackberry diseases and Insects, 2nd ed. American Phytopathological Society, St. Paul, MN, U.S.A.

Medema, M. H., Blin, K., Cimermancic, P., de Jager, V., Zakrzewski, P., Fischbach, M. A., Weber, T., Breitling, R., and Takano, E. 2011. antiSMASH: Rapid identification, annotation and analysis of secondary metabolite biosynthesis gene clusters. Nucleic Acids Res. 39:W339-W346.

Osterwalder, A. 1911. Über eine neue auf kranken Himbeerwurzeln vorkommende Nectria und die dazu gehörige Fusarium-Generation. Ber. Dtsch. Bot. Ges. 29: 611-622.

Rivera, Y., Salgado-Salazar, C., Veltri, D., Malapi-Wight, M., and Crouch, J. A. 2018. Genome analysis of the ubiquitous boxwood pathogen Pseudonectria folicola. PeerJ 6:e5401.

Salgado-Salazar, C., and Crouch, J. A. 2019. Genome resources for the stem and bark canker pathogens Corinectria fuckeliana, Neonectria hederae and N. punicea. Plant Dis. 103:389-391.

Salgado-Salazar, C., Rossman, A. Y., and Chaverri, P. 2016. The genus Thelonectria (Nectriaceae, Hypocreales, Ascomycota) and closely related species with cylindrocarpon-like asexual states. Fungal Divers. 80:411-455.

Salgado-Salazar, C., Rossman, A. Y., Samuels, G. J., Hirooka, Y., Sanchez, R., and Chaverri, P. 2015. Phylogeny and taxonomic revision of Thelonectria discophora (Ascomycota, Hypocreales, Nectriaceae) species complex. Fungal Divers. 70:1-29. 